\title{
Trabajo industrial y dinámicas socioterritoriales en las ciudades de Ensenada y Berisso. El caso de la Refinería YPF- La Plata (1993-2012)
}

\section{Industrial work and socio-territorial dynamics in the cities of Ensenada and Berisso. The case of the Refinery YPF-La Plata (1993-2012)}

Sandra Valeria Ursino

Doctora en Arquitectura y Urbanismo. Centro Interdisciplinario de Estudios Complejos. Facultad de Arquitectura y Urbanismo. Universidad Nacional de La Plata (CIEC/FAU/UNLP). Calle $47 N^{\circ} 162$, (1900) La Plata, Buenos Aires,

Argentina, sandraur@hotmial.com, ORCID https://orcid.org/0000-0002-6136-5105

Recibido: 26 de septiembre 2019 || Aprobado: 2 de julio 2020

Resumen

En este trabajo se analiza el impacto social, económico y territorial que tuvo la privatización de La Refinería YPF-La Plata en las ciudades de Ensenada y Berisso en el año 1993, y cómo se reconfiguraron a partir de la vuelta a manos del Estado en el año 2012. Una de las características centrales de la empresa petrolera estatal fue su gestión paternalista, la cual atravesaba los espacios de la vida cotidiana de sus trabajadores, la familia y la comunidad. A partir de la privatización surgieron nuevos tipos de contrataciones y un entramado industrial conformado por Pymes y Cooperativas de Trabajo que introdujeron fuertes cambios tanto en el mundo del trabajo "ypefeano" como en la dinámica urbana de ambas ciudades. Se utilizó una metodología cualitativa flexible basada en entrevistas en profundidad a trabajadores y ex trabajadores de la refinería, funcionarios públicos y representantes gremiales. Se complementó con el registro de organismos del Estado como OPDS, ADA e información censal del INDEC.

Palabras clave: Trabajo industrial; Dinámicas socioterritoriales; Ciudades medias; Refinería YPF-La Plata

Abstract

This work analyzes the social, economic and territorial impact of the privatization of the YPF-La Plata Refinery in the cities of Ensenada and Berisso in 1993, and how they were reconfigured after the return to the hands of the State in the 2012. One of the central characteristics of the state oil company was its paternalistic management, which crossed the spaces of the daily life of its workers, the family and the community. After the privatization, new types of contracting and an industrial framework made up of SMEs and Worker Cooperatives emerged, introducing strong changes in the YPF working environment as well as in the urban dynamics of both cities. A flexible qualitative methodology was used, based on in-depth interviews with refinery workers and ex-workers, public officials and union representatives. It was complemented by the registration of State agencies such as OPDS, ADA and census information from INDEC.

Key words: Industrial work; Socio-territorial dynamics; Medium-sized cities; Refinery YPF -La Plata

Cita sugerida: Ursino, S.V. (2020). Trabajo industrial y dinámicas socioterritoriales en las ciudades de Ensenada y Berisso. El caso de la Refinería YPF-La Plata (1993-2012). Estudios Socioterritoriales. Revista de Geografía, (28), 057. DOI: https://doi.org/10.37838/ unicen/est.28-057 
INTRODUCCIÓN

En esta investigación se analiza la importancia del trabajo industrial en la dinámica territorial de dos ciudades intermedias como es el caso de Ensenada y Berisso, haciendo énfasis en uno de los establecimientos productivos más importantes de la zona: la Refinería YPF-La Plata.

La instalación de la empresa en el año 1922 en la ciudad de Ensenada, marcó el perfil de la región dado que generó múltiples dinámicas en el territorio de gran impacto a nivel urbano, social, económico y ambiental. La gestión paternalista de YPF atravesó la vida comunitaria de ambas ciudades como también los espacios cotidianos de sus trabajadores y familia. Este rol fue central para el desarrollo de las fuerzas productivas, dado que se entrecruzaron lógicas de poder subyacentes propias de la importancia del trabajo en la vida familiar y comunitaria.

Con el paso del tiempo, este tipo de gestión empresarial se modificó junto con el tipo de vinculación que tenía la empresa con el trabajador y su familia. A partir de la privatización en el año 1993, la estructura social de ambas ciudades fue afectada fuertemente por la cantidad de despidos, como también por los nuevos tipos de contrataciones que surgieron producto de la flexibilización y terciarización laboral. Este nuevo escenario introdujo cambios en el mundo del trabajo 'ypefeano' y modificó la dinámica urbana de Berisso y Ensenada. La terciarización y precarización laboral que se implementó en la Refinería abrió un abanico de contrataciones, donde algunos ex trabajadores se organizaron en pequeñas empresas que posteriormente la abastecieron, y de este modo, conformaron un mapa de Pymes con fuerte implicancia a escala territorial y social.

Respecto a las dinámicas socio-territoriales que generó este establecimiento industrial, muchos estudios se han centrado en un análisis de carácter macrosocial -poniendo el acento en los procesos productivos y económicos nacionales hasta llegar a la escala local- (Adriani, 2014; Adriani, Langard y Steimberg, 2011; Azpiazu y Basualdo, 2004; Basualdo, 2006; Beccaria, Esquivel y Maurizio, 2000; Bonnet, Figueiredo y Standing, 2003; Frassa, Muñiz Terra y Nacleiro, 2010, entre otros), mientras que otros trabajos se orientan a observar los cambios sociohistóricos en el mundo de los trabajadores, a través del estudio de la experiencia fabril así como del proceso de formación de identidades, la resistencia obrera, el sindicalismo, las trayectorias laborales, la desocupación y los movimientos piqueteros, principalmente en el momento de su privatización y durante la aplicación de la políticas neoliberales (Lobato, 2001; Ciffarelli y Martínez, 2009; Figari y Palermo, 2010; Muñiz Terra, 2007, 2008; Torres, 2011, 2012, entre otros).

A partir de estos estudios, se pretende realizar un aporte que incorpore ambos análisis y contemple las dinámicas socioterritoriales que generó la empresa con la privatización, conformando un nuevo entramado industrial de Pymes que se diseminaron por el territorio, lo cual generó a nivel urbano mayor demanda de infraestructura física, diversificación de la actividad industrial y terciarización de varios procesos, entre ellos la obra civil. Esto tuvo un fuerte impacto en la vida y en los espacios cotidianos de los trabajadores y sus familias, por lo tanto, se propone un análisis que integre la dimensión material y simbólica de la actividad industrial en ciudades medias, como Berisso y Ensenada.

El nuevo tipo de contratación atravesó los espacios de la vida cotidiana de los trabajadores, dado que el vínculo con la empresa se tornó más flexible y precario con fuerte incidencia en las relaciones laborales. Asimismo, la proliferación de Pymes en ambas 
ciudades condicionaron la dinámica socio territorial de las mismas, donde el espacio barrial circundante se encuentra tensionado por un conjunto de actividades que antes se hacían en un solo lugar: la empresa.

La pesquisa se aborda con una metodología cualitativa con diseño flexible, basada en la importancia del relato y la representación gráfica. Se diseñó una muestra poblacional emplazada en las ciudades de estudio, donde se realizaron entrevistas en profundidad a ex trabajadores, trabajadores actuales e informantes clave ${ }^{1}$. El alcance de la muestra fue realizado por la estrategia bola de nieve ${ }^{2}$, que es una técnica de recolección de datos utilizada en la investigación cualitativa para la realización de entrevistas individuales (Goodman, 1961). Una vez identificadas las primeras personas que serán entrevistadas, mediante estas se consiguen otros contactos, hasta completar la muestra y la cantidad de informantes necesaria para obtener representatividad. En este caso, las decisiones se tomaron en relación a los motivos de despido, la antigüedad en la empresa y el barrio donde viven en la actualidad Se identificó a un informante clave -médico del sindicatoque nos contactó con un ex trabajador y así sucesivamente, teniendo en cuenta el criterio de saturación y factibilidad en la realización de la muestra.

Por medio del relato y la fotografía se reconstruyeron las vivencias de los trabajadores y ex trabajadores de la empresa. Se complementó con la utilización de fuentes secundarias del Organismo Provincial para el Desarrollo Sostenible (OPDS), la Autoridad del Agua y los censos económicos, que permitió ubicar geográficamente al conjunto de Pymes que actualmente tienen conexión y realizan trabajos para la Refinería YPF-La Plata. La vinculación de datos permitió analizar las principales dinámicas socioterritoriales que genera la Refinería en ciudades medias, como Berisso y Ensenada, y en la vida de sus trabajadores en particular.

\section{La Refinería YPF-La Plata en las ciudades de Ensenada y Berisso: ubicación e impacto TERRITORIAL}

En el año 1925, en el área portuaria del actual Gran La Plata, se construyó el mayor establecimiento industrial de la región, la Refinería YPF-La Plata (Figura 1). Los principales factores de localización fueron las instalaciones portuarias, necesarias para disponer del insumo básico, y la proximidad de Buenos Aires, principal mercado consumidor de la Argentina. Es la mayor refinería del país y actualmente cuenta con una capacidad de refinación de 189.000 barriles por día. Tiene la capacidad de procesar todas las variedades de crudo producidas en el país para obtener una amplia gama de productos. Además, forma parte del Complejo Industrial La Plata de YPF que cuenta también con capacidad de elaboración de bases lubricantes, parafinas, extractos aromáticos y asfaltos y diferentes productos petroquímicos (YPF, s/f).

Generalmente, los lugares donde se realizaba la actividad extractiva del recurso petróleo, como los situados en la Patagonia, se ubicaban en áreas que en los momentos iniciales de la expansión de YPF se hallaban con escaso número de habitantes ${ }^{3}$. No obstante, otros,

1 El trabajo de campo se realizó para la tesis doctoral, y consistió en 44 entrevistas en profundidad: 18 ex trabajadores, 13 trabajadores actuales, 5 familiares y 8 informantes clave (represente gremial SUPHE y representantes del Área municipal de Planeamiento urbano), durante los años 2015-2018.

2 En inglés se denomina snowball sampling.

3 Sobre estos casos son relevantes los estudios de Palermo (2015) quien analiza las relaciones laborales, el proceso de formación de identidades y las tensiones sociales que se dan en ciudades petroleras, como Comodoro Rivada- 
como aquellos en los que se ubicó la Refinería YPF-La Plata, eran núcleos urbanos más consolidados (Figura 2).

Figura 1. Foto aérea de la Refinería YPF-La Plata, inicio de actividades año 1925

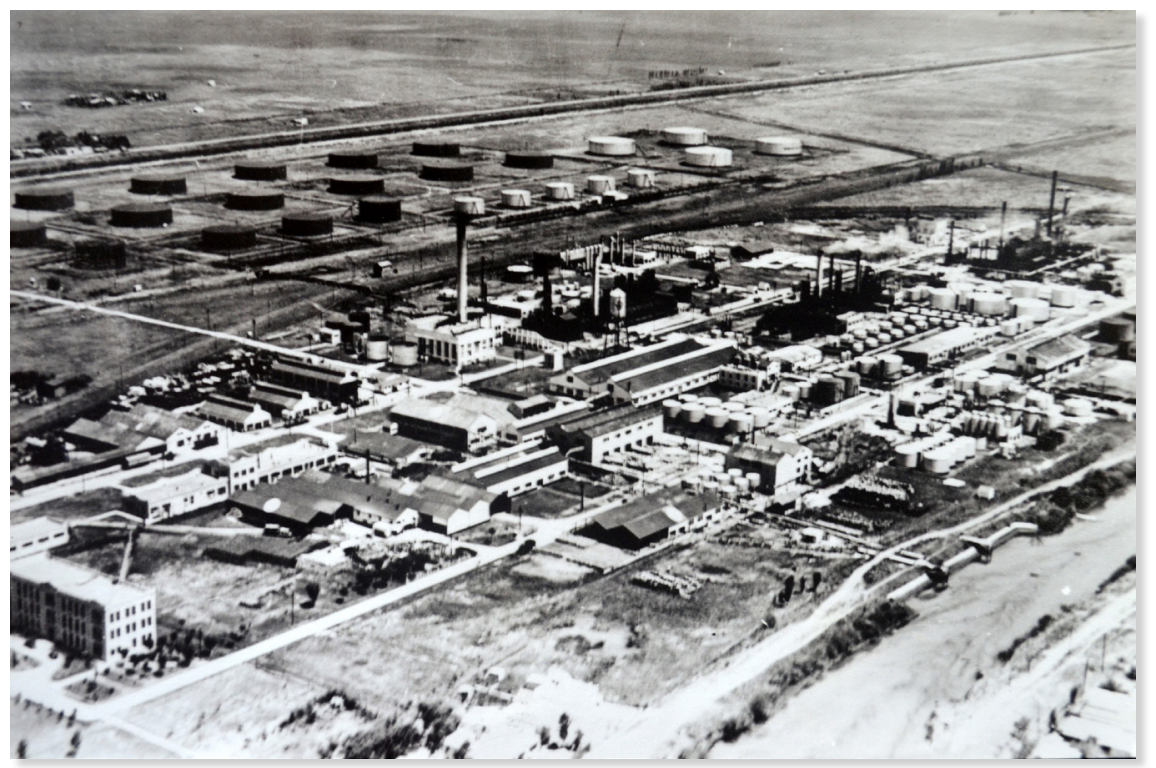

Fuente: Archivo de la Biblioteca Municipal de Ensenada Baldomero Fernández Moreno, registro de trabajo de campo, agosto 2016

Figura 2. Periodo de expansión urbana 1910-1940 con la instalación de la Refinería YPF- La Plata

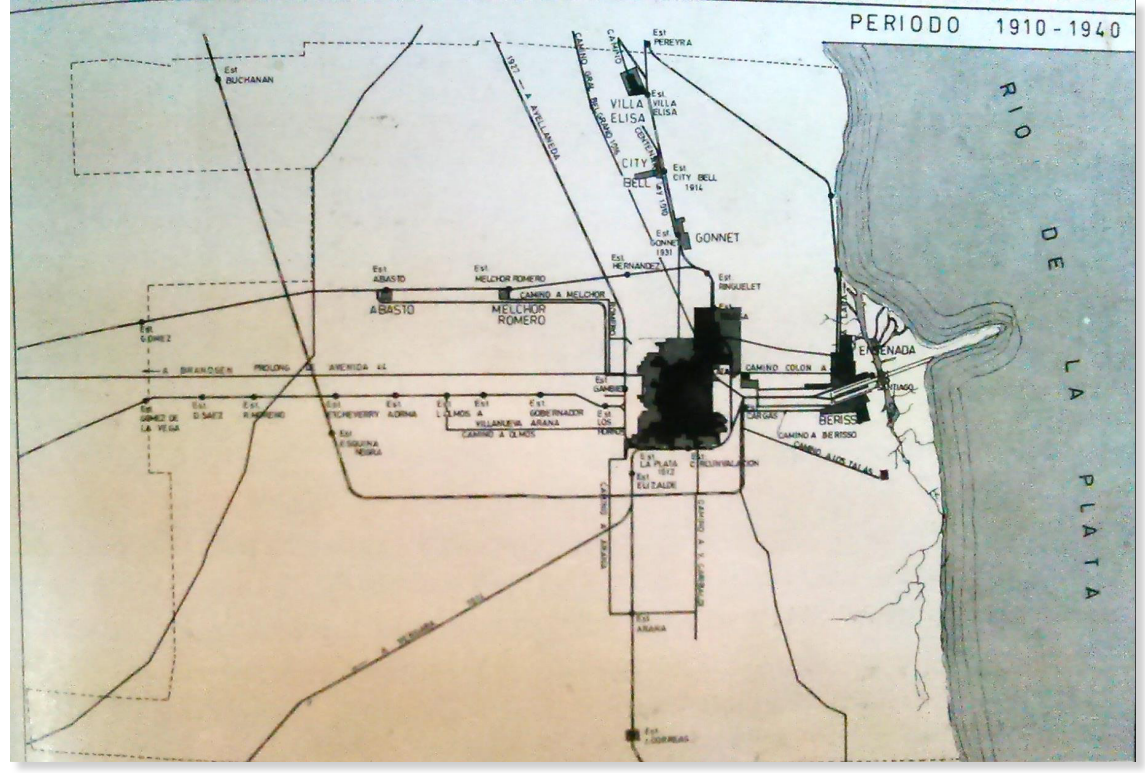

Fuente: La Plata, Ciudad nueva, Ciudad antigua. Morosi (1983)

En ambos casos, la modalidad de ocupación del territorio se basó en una estrategia de construir tanto establecimientos productivos como ámbitos específicos para la reproducción de la fuerza de trabajo que se apoyó en equipamiento social: viviendas,

via. El autor estudia los conflictos sociales en la ciudad a partir de trabajar en YPF y por los beneficios económicos que la empresa le otorga a estos empleados (nivel de salario y poder adquisitivo), como también, las dinámicas familiares y las relaciones vecinales entre los trabajadores del petróleo y el resto de la comunidad. 
centros de salud, espacios recreativos, sedes educativas, etc., que dieron lugar a la conformación y consolidación de los barrios obreros. En varios de los establecimientos de la empresa se implementó una política sociolaboral que ayudaba a la familia del trabajador. La perspectiva de esta política se centraba en mantener al trabajador y a sus hijos como potencial fuerza de trabajo mientras la mujer cumplimentaba el rol de cuidar la familia y la vivienda. Estas condiciones contribuyeron a que YPF se constituyera en un importante promotor de desarrollo urbano y regional. El tipo de gestión paternalista que tenía la empresa no se circunscribía solo a la esfera productiva sino que también modificó la estructura urbana, dado que construyó en sus proximidades los barrios Este y Oeste destinados a los operarios y sus familias. El personal más calificado, el técnico y los directivos residieron en un predio especial dentro de la planta industrial. A partir de la conformación del sindicato SUPE (Sindicatos Unidos Petroleros del Estado) se ampliaron las políticas sociales para los trabajadores de la Refinería y en las décadas de 1940 y 1950 se terminó de construir todo el equipamiento social necesario para los mismos (Muñiz Terra, 2012).

En esta dirección Russo (2008) y Muñiz Terra (2007), plantean que el paternalismo es un método de control y gestión que se establece en los vínculos entre el empresario y los operarios, y adopta diversas formas en relación al tiempo y al lugar como a la justificación ideológica que se le da para su implementación.

El paternalismo es una respuesta a la clásica asimetría en la inserción productiva de las clases sociales en la relación capital-trabajo, y se expresa, por un lado, en el monopolio de los medios de producción (máquinas, fuerza motriz, materia prima, etc.), y por el otro, en la inserción productiva de la mano de obra en dicho proceso. Sin embargo, implica una realidad social en un determinado territorio donde se establecen los asentamientos obreros organizados y estimulados por el patrón paternalista como símbolo de dominio socio-territorial (Russo, 2008).

En esta dirección, Russo retoma de Guiotto (1979) las dos etapas básicas del paternalismo industrial. La primera refiere al protopaternalismo y corresponde al periodo inicial de la industrialización y a la creación de algunas instituciones vinculadas a la empresa y a cierta infraestructura urbana. Se trata de fijar la vida y la cotidianeidad de los trabajadores en torno a la fábrica. En esta etapa, la intervención central tiene que ver con construir una infraestructura urbana básica que exige la radicación de la industria. Esta configuración micro-territorial es la forma más elemental de establecer y generar lazos con la población trabajadora y su familia.

La segunda fase, el paternalismo maduro, busca el pleno involucramiento -no solo económico sino también ideológico- del trabajador con los objetivos productivos de la empresa. De este modo, se influye en la vida de la familia y en los espacios que forman parte de su vida cotidiana, es decir, la vida comunitaria donde se establece la fábrica. El paternalismo funciona como un complejo aparato de integración y organización del consenso. Ejerce un fuerte condicionamiento y posee una capilaridad que atraviesa los aspectos más privados de la vida de la familia obrera (Russo, 2008). En el caso de YPF, ello se observa en las publicaciones semanales de la revista Seguridad Industrial, que la empresa emitía para sus trabajadores, donde además de dar consejos sobre la actividad laboral lo hacía también sobre el desempeño del trabajador en la vida familiar y social.

Este tipo de gestión estuvo vinculada a la necesidad de reclutar mano de obra disciplinada que permitiera el traspaso de un modo de producción tradicional a otro indus- 
trial. En el caso de un país agroexportador como Argentina, había que atraer mano de obra al sector industrial, pero era difícil debido a que la misma era monopolizada en su mayoría por la actividad rural. Esto último llevó a la necesidad de poblar atrayendo mano de obra inmigrante. Un claro ejemplo de lo expresado se da en los frigoríficos Swift y Armour de Berisso, cuyos trabajadores eran en gran parte inmigrantes.

A su vez, el pasaje de una mano de obra fluctuante a otra de carácter estable, exigía disciplinamiento. El trabajo en la fábrica implicaba una jornada laboral marcada por ritmos precisos de actividad ininterrumpida, durante todos los días de la semana, en espacios cerrados y en colaboración con otras personas. Este sistema daba resultados por la intervención directa del empresario a fin de organizar la vida productiva a escala micro-territorial (Russo, 2008).

Por lo tanto, la producción industrial en la Argentina del siglo XX se basó en la estructuración de nuevas relaciones sociales que se expresaban en la división social del trabajo y en el orden dentro del ámbito laboral. Simultáneamente, este cambio en el tipo de gestión empresarial tenía el poder de penetrar en la vida individual y asociativa del trabajador. Dicho paternalismo adquiría notoriedad en el terreno de la vida familiar, en los lugares de encuentro y sociabilidad, en las instituciones asistenciales y en toda actividad social que se llevaba adelante en las zonas donde se instalaban. En las ciudades de estudio se fue conformando un paisaje industrial que -por medio de huellas y marcas en el territorio- expresó tanto la actividad económica como simbólica que se generó en estos espacios urbanos con características particulares.

La empresa tuvo gran influencia en el crecimiento urbano de la zona donde la actividad humana, el soporte natural, los límites político-administrativos, la vida comunitaria y política, fueron características centrales que participaron en la construcción de un área industrial y portuaria de gran relevancia para la futura región del Gran La Plata. Estos condicionantes, se vinculan con la fundación de la ciudad de La Plata, dado que la ubicación de la Refinería se asienta sobre un eje puerto-industria-ciudad basado en las ideas higienistas de la época ${ }^{4}$. Al momento de su fundación, el partido de La Plata abarcó los territorios de Ensenada y Berisso hasta el año 1957, cuando se dividió en tres partidos supuestamente para mejorar la administración de un área que atraía cada vez más población (Pesoa y Sabaté, 2016). En el proyecto fundador de La Plata, hacia el exterior de la Avenida Circunvalación se pensó un sistema de anillos periféricos de quintas y chacras para el abastecimiento local de productos primarios y de abastecimiento regional y nacional de productos agropecuarios. El puerto permitía la llegada de embarcaciones hasta las puertas de la ciudad, generando autonomía con respecto a la capital nacional. De este modo, la actividad del puerto y la industria quedaba en parte delimitada a Berisso y Ensenada, y la actividad administrativa y de servicios a La Plata. Parte de lo mencionado, tuvo un impacto directo en la forma urbana y tal como se muestra en las Figuras 2 y 3, la región fue creciendo al ritmo de la industria.

En la década de 1960 la Refinería se consolidó como núcleo del Polo Petroquímico Ensenada, el cual está conformado por las siguientes empresas: Industrias Petroquímicas Köppers (IPAKO), productora de etileno y polietileno, radicada en el año 1962 en producción hasta su cierre en el año 1998; Petroquímica General Mosconi (PGM) inaugurada en el año 1974. Junto a esta última, se situaron Maleic en el año 1981 para

4 En este trabajo se recuperan algunas ideas del higienismo, pero no se profundiza en el concepto. Para ello se recomienda Pesoa y Sabaté (2016); Ravella y Giacobbe (2001); Morosi (1999). 
producir anhídrido maleico, y Polibutenos Argentina emplazada en el año 1982 para la producción de polibutenos. En el año 1983 se instala en predios del puerto la empresa COPETRO para la producción de carbón de petróleo calcinado, y en el año 1992 abre la fábrica de polipropileno Petrokén (Adriani y Arturi, 2015).

Figura 3. Período de expansión urbana 1940-1982

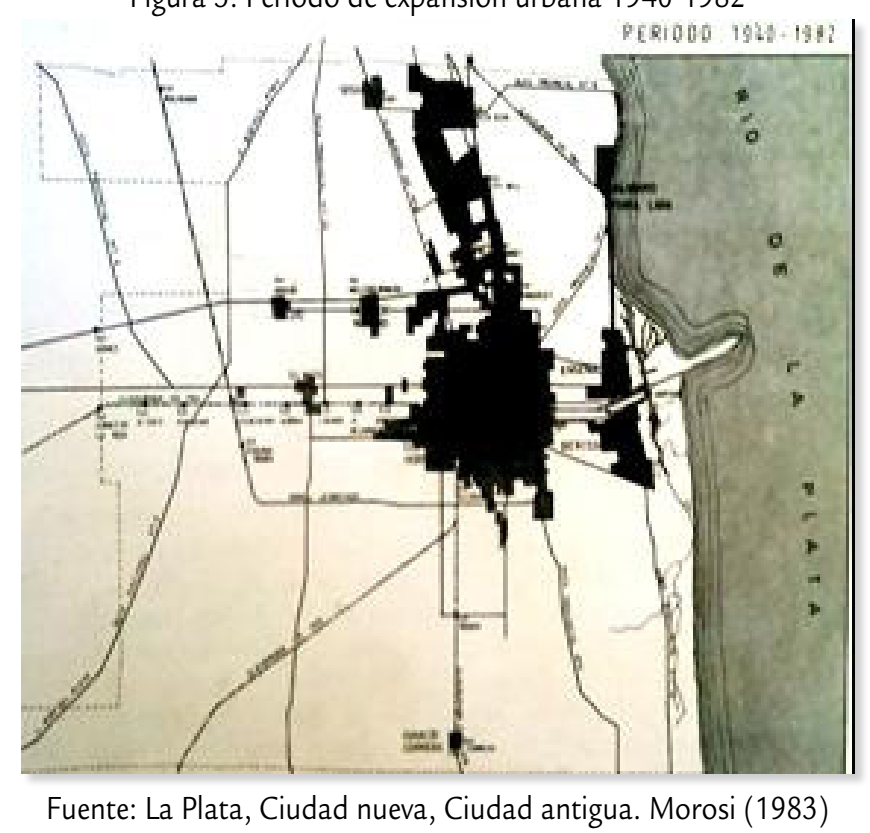

Durante más de 50 años la Refinería YPF-La Plata articuló con las otras grandes empresas de Ensenada: Astillero Río Santiago, Propulsora Siderúrgica y Petroquímica General Mosconi. Con las empresas siderúrgicas se vinculó para la construcción de tanques de almacenamiento e infraestructura interna, con Petroquímica para sustituir importaciones y desarrollar el sector de parafinas y con Astilleros para la movilización social y sindical. Estas relaciones económicas y políticas la convirtieron en un eje fundamental en la construcción comunitaria e identitaria de la población de Berisso y Ensenada.

A partir de la sanción de las leyes de reforma del Estado y Emergencia Económica del año 1989 se implementaron medidas neoliberales que dieron lugar a una mayor desregulación y apertura de la economía, a la privatización de empresas y activos públicos, y a la descentralización administrativa. La aplicación de estas leyes se manifestó directamente en los índices de ocupación de los dos municipios (Tabla 1), dado que la cantidad de trabajadores industriales fue decayendo abruptamente: según los censos nacionales económicos en el año 1974, Ensenada contaba con 14.004 y Berisso con 6.147, pasando en el año 1985 este último a 1.596 y Ensenada a 8.862 puestos de trabajo. Sin embargo, la caída más abrupta se registró en el periodo intercensal 1985-1994, donde Ensenada registró 3.683 y Berisso 906. Es en el año 2004 donde hay un leve ascenso de 4.260 puestos para Ensenada, manteniéndose prácticamente la misma cantidad en Berisso (INDEC, 1974, 1985, 1994 y 2004).

En el año 1990 trabajaban en la Refinería YPF-La Plata alrededor de 4.400 empleados de los cuales 1.350 pertenecían al sector de producción y el resto se desempeñaba en los sectores de administración y mantenimiento. En el año 1991 unos 1.000 empleados contratados por YPF para tareas de mantenimiento y construcción, pertenecientes a las 
empresas SADE y Techint, pasaron a formar parte de la planta de la empresa petrolera estatal. Esto motivó paralelamente el traspaso del personal del sindicato de la construcción (UOCRA) al sindicato petrolero (SUPE) (Berberena y Marcos, 1997).

\begin{tabular}{lrrrr}
\multicolumn{5}{c}{ Tabla 1. Cantidad de trabajadores industriales } \\
\hline Municipio & \multicolumn{1}{c}{1974} & \multicolumn{1}{c}{1985} & \multicolumn{1}{c}{1994} & \multicolumn{1}{c}{2004} \\
\hline Ensenada & 14.404 & 8.862 & 3.863 & 4.260 \\
\hline Berisso & 6.147 & 1.596 & 906 & 906
\end{tabular}

Fuente: elaboración personal con base en datos del Censo Nacional Económico (1974, 1985, 1994 y 2004)

La plantilla de trabajadores en esta Refinería fue reducida en un $89 \%$, y pasó de tener 5.400 trabajadores en el año 1991 a 600 en el año 1994. Es decir, cerca de 4.800 empleados quedaron en la calle. A su vez, la desvinculación fue realizada de tres formas diferentes: el retiro voluntario; la obligatoriedad de capacitación laboral con salarios pagos y cobertura social; y la tradicional forma de despido (Muñiz Terra, 2008).

La privatización fue acompañada de una importante reestructuración productiva que incluyó la política de racionalización de personal mencionada, cuya consecuencia inmediata fue la desvinculación de una gran cantidad de trabajadores, además de la flexibilización y terciarización laboral.

Ante este escenario, el Estado argentino, a través de su empresa estatal YPF, impulsó la generación de emprendimientos productivos de menor magnitud para poder desprenderse sin conflicto de gran parte de su planta de trabajadores, logrando no solamente apaciguar el conflicto social que podría haberse generado con todos los trabajadores despedidos y sin trabajo, sino además generando una oferta de servicios que a Repsol-YPF, ya privatizada, le fue útil sostener, a un precio más conveniente para su estrategia empresarial. Esto no ocurrió en otras zonas del país, dado que donde se realizaba la actividad de extracción del petróleo, la conflictividad social fue álgida y generó los primeros piquetes y cortes de ruta de gran repercusión en el derrotero de manifestaciones populares (Bazalote y Radovich 2000; Torres, 2012; Svampa y Pereyra, 2009; Cotarelo, 2005).

En este período la economía argentina se caracterizó por el estancamiento y la recesión. Como señalan Langard, Arturi y Adriani (2012) los principales rasgos del momento fueron: fuertes oscilaciones de incremento y caída del PBI, caída de la inversión, expansión del sector financiero íntimamente vinculada al endeudamiento externo, deterioro del mercado de trabajo y los salarios, y concentración del ingreso. Entre los distintos sectores económicos, el sector industrial fue particularmente afectado por dichas políticas.

Durante esta etapa se profundizaron los procesos de desindustrialización y reestructuración heterogénea y regresiva iniciados desde mediados de la década de 1970, los cuales fueron asimilados de manera diferencial por el sector industrial y dependieron del tipo de inserción de las empresas en la estructura económica, sus trayectorias, tamaño, límites y capacidades, profundizándose así la mencionada reestructuración heterogénea y regresiva iniciada en los períodos anteriores (Langard et al., 2012) .

Tal como desarrolla Odisio (2015), el sector petrolero y petroquímico estaba compuesto, previamente al proceso de privatización y concentración, por la Refinería YPFLa Plata, Petroquímica General Mosconi, IPAKO, Maleic, Polibutenos Argentinos y Petroken. Luego de la desregulación del mercado de hidrocarburos y de la privatización de 
YPF, se produjo en este polo un fuerte proceso de integración vertical y concentración empresarial. En este conjunto de empresas es importante destacar el rol que tuvo la Petroquímica General Mosconi, dado que fue una de las principales inversiones del Estado nacional en la rama petroquímica con el objetivo de sustituir importaciones. Se originó en el año 1969 a partir de la asociación de YPF y la Dirección Nacional de Fabricaciones Militares. Inaugurada en el año 1974 se transformó en una de las principales empresas de la región, con importantes niveles de productividad y exportación producto de la tecnología incorporada y sus capacidades productivas. En la década de 1980 la empresa llevó a cabo numerosas inversiones que la transformaron en la industria argentina de mayor inversión y la de mayor capacidad productiva en la rama petroquímica, enfrentando las restricciones económicas de ese período (Odisio, 2015).

En el contexto de las políticas de reforma del Estado, en el año 1992, se dictó el decreto de privatización de la Petroquímica y para comienzos del año 1993 ya se habían despedido de la planta a más de 500 trabajadores. Ese mismo año YPF tomó el control y absorbió la Petroquímica General Mosconi integrando sus plantas bajo la denominación de Petroquímica La Plata (PLP).

Poco después, en el año 1994, YPF adquirió a IPAKO y amplió su participación en Petroken y a fines de la década adquirió y absorbió a Polibutenos Argentinos -por ese entonces División Petroquímica de Bridas- y a Maleic. Con estas acciones de concentración, YPF quedó como el principal actor económico y productivo en el polo de Ensenada, condición que mantiene hoy en día. En el año 2002 IPAKO cerró definitivamente luego de haber iniciado un proceso de reducción de su actividad económica en el año 1998.

En el año 2012 la nacionalización de la mayor parte de sus acciones abrió nuevas perspectivas y proyectos, entre ellos el establecimiento en el municipio de Berisso de laboratorios de investigación y desarrollo y la nueva sede de YPF Tecnología (Figura 4), creada por YPF, el Ministerio de Ciencia, Tecnología e Innovación Productiva y el CONICET. Su objetivo consiste en desarrollar investigaciones tecnológicas aplicadas sobre petróleo y gas.

El anuncio de esta medida por la ex presidente de la Nación Cristina Fernández de Kirchner generó expectativas en la población de la región, pero principalmente de la comunidad científica puesto que se planteaba así la posibilidad real de generar avances científicos y tecnológicos sobre la industria del petróleo y sus derivados.

Figura 4. YTEC CONICET, inicios de la obra

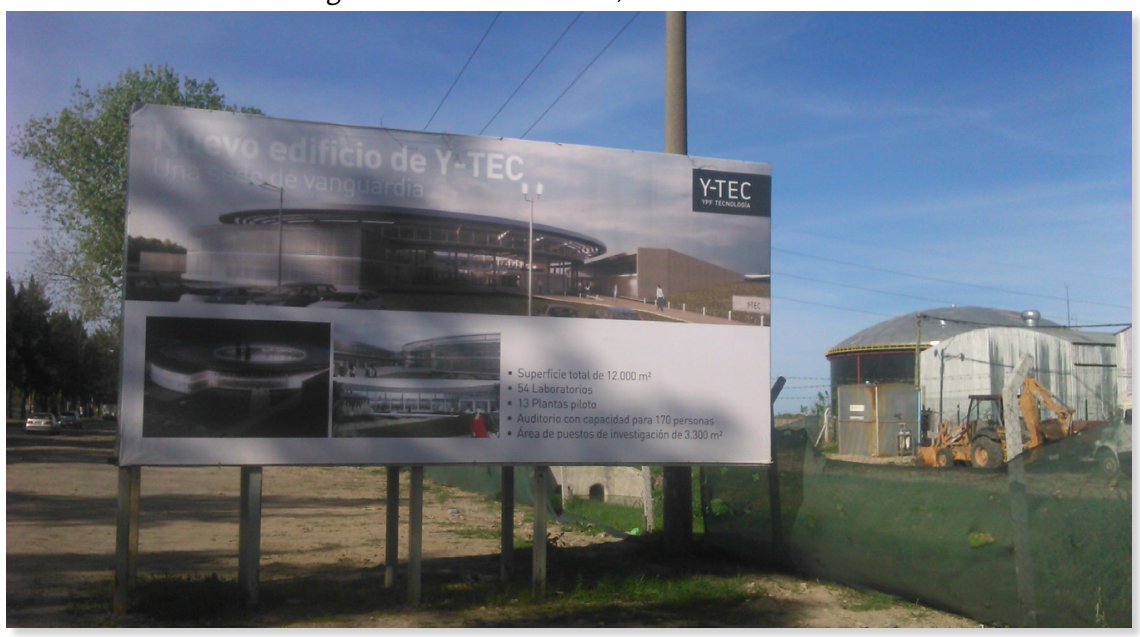

Fuente: Registro de trabajo de campo, septiembre de 2014 
En conclusión, y como lo han afirmado parte de los autores trabajados (Muñiz Terra, 2012; Adriani et al., 2011), la Refinería YPF-La Plata es una empresa que ha marcado los ritmos de la inversión económica e industrial en la región acorde al modelo de desarrollo imperante. De esta manera, la firma creció y se diversificó en función de la demanda interna y externa cuando a nivel nacional se propuso desarrollar una matriz económica y productiva basada en el fortalecimiento del mercado interno, las Pymes, el sector metalúrgico y el petrolero. Sin embargo, cuando se aplicaron medidas de corte neoliberal amparadas en el libre mercado y las importaciones, la capacidad productiva de YPF se limitó a las demandas cíclicas de un sector productivo que redujo poco a poco su margen de actuación.

A escala local, el impacto de la empresa se expresa en la calidad de vida de la población y en la cantidad de trabajadores, dado que el funcionamiento de la firma se encuentra ligado a un entramado de Pymes y cooperativas que trabajan para ella y que ocupan mano de obra en función a la demanda del sector productivo. Esto se debe en parte a la precariedad de un mercado de trabajo que nunca se recuperó post privatización y que aún persiste a pesar de la vuelta al Estado, tal como se desarrollará a continuación.

\section{PrivatizaCión, RENACIONALIZACIÓN Y NUEVAS PRÁCtICAS INDUSTRIALES EN El TERRITORIO}

Parte de la herencia del periodo neoliberal fue el desempleo, la pobreza y la precarización laboral. En este marco de crisis del régimen de convertibilidad, se pasó de las grandes empresas -principalmente del Estado- a la constitución de Pymes y cooperativas como una forma de resistencia y supervivencia de los trabajadores ante la pérdida acelerada de la fuente de trabajo.

No obstante, el proceso de recuperación de fábricas en la Argentina se inicia antes de la crisis de la convertibilidad, es decir, a fines de los años 1990 y principios del año 2000, donde adquiere mayor protagonismo, extendiéndose este proceso a diferentes regiones del país. Durante la década de 1990 la aplicación de políticas neoliberales significó la desestabilización y debilitamiento de numerosas ramas industriales, unidades productivas y consecuentemente de la fuerza de trabajo.

Tal como expresan Ardenghi y Adriani (2014), las reformas estructurales a escala económica e industrial se enmarcaron en el cambio de paradigma tecno-productivo de la crisis del fordismo. Las características principales fueron: la transnacionalización de empresas multinacionales, el achicamiento o quiebra de pequeñas y medianas empresas locales, el debilitamiento de organizaciones sindicales tradicionales, el miedo a la lucha por derechos laborales, la polifunción de los trabajadores, la reducción de costos de mano de obra y la precarización e inestabilidad laboral, entre otros.

Ante esta crisis económica y también política e institucional los sectores populares buscaron por todos los medios preservar su fuente de trabajo. La recuperación de fábricas se convirtió en una estrategia más de supervivencia, que se fortalecía junto al desarrollo de redes de sociabilidad barrial afirmadas en el hecho de compartir cotidianamente una situación crítica como los despidos masivos, el cierre de fábricas o la precarización laboral.

Entre los años 1991 y 1992 surgieron alrededor de veinte emprendimientos, formados predominantemente por ex empleados del sector mantenimiento de la Refinería ${ }^{5}$. Du-

5 La refinería estaba conformada por tres sectores: producción, administración y mantenimiento. 
rante el año 1993 se agregaron algunos más totalizando alrededor de treinta. Algunas de estas empresas tuvieron corta vida quedando actualmente once de las originales. Estos emprendimientos fueron creados para ofrecer el mismo servicio que antes prestaban en el interior de la empresa. Su conformación estuvo liderada en la mayoría de los casos por el sindicato petrolero SUPEH, adoptando algunos la forma de cooperativa de trabajo, otras constituyeron sociedades anónimas y otras sociedades de responsabilidad limitada. A su vez, la empresa petrolera ya reconvertida subcontrató también a empresas preexistentes no necesariamente compuestas por ex empleados, como fue el caso de Media Caña, Nepea, Petal, Copetro, entre otras.

Cuando me echan de YPF formamos las famosas cooperativas. Nosotros formamos la cooperativa de transporte y estuve hasta el año 97 ahí. Y después me quedé con el taxi. Porque yo cuando me voy de YPF, con la indemnización me compré un departamentito en La Plata y el taxi. Yo cobré buena plata de indemnización porque tenía muchas horas... Yo estuve diez años trabajando de lunes a lunes... (Roberto, 74 años, ex trabajador de YPF)

Es durante la posconvertibilidad donde se asistió a una etapa de recuperación y posterior crecimiento de la actividad económica, y donde este tipo de emprendimiento tuvo su mayor protagonismo. Este nuevo escenario político-institucional y económico brindó determinados condicionantes que apoyaron la consolidación de las fábricas recuperadas: el crecimiento del mercado interno, principal destino de su producción, y la implementación de varios programas de apoyo por parte de organismos estatales contribuyeron a su fortalecimiento y continuidad. Aunque numerosas problemáticas jurídicas, políticas y económicas continúan dificultando su posibilidad de crecimiento y expansión (Adriani y Ardenghi, 2014).

En el caso de la Refinería YPF-La Plata, el proceso de privatización expulsó a una gran cantidad de trabajadores sumamente especializados en la actividad. A través de diversas estrategias de organización y negociación con la propia empresa y el Sindicato SUPEH, los empleados despedidos fundaron la Cámara de Emprendimientos y Empresa del Polo Petroquímico.

A partir del año 2004, y debido al crecimiento de la actividad industrial, este tipo de emprendimientos se fue expandiendo, principalmente en las ciudades de Berisso y Ensenada. El incremento de la actividad se puede apreciar a escala territorial con mayor detalle en la Figura 5, en la cual se visualiza la conformación de un polígono industrial consolidado en la región. 
Figura 5. Registro cartográfico de principales empresas y de Pymes de la región, año 2016

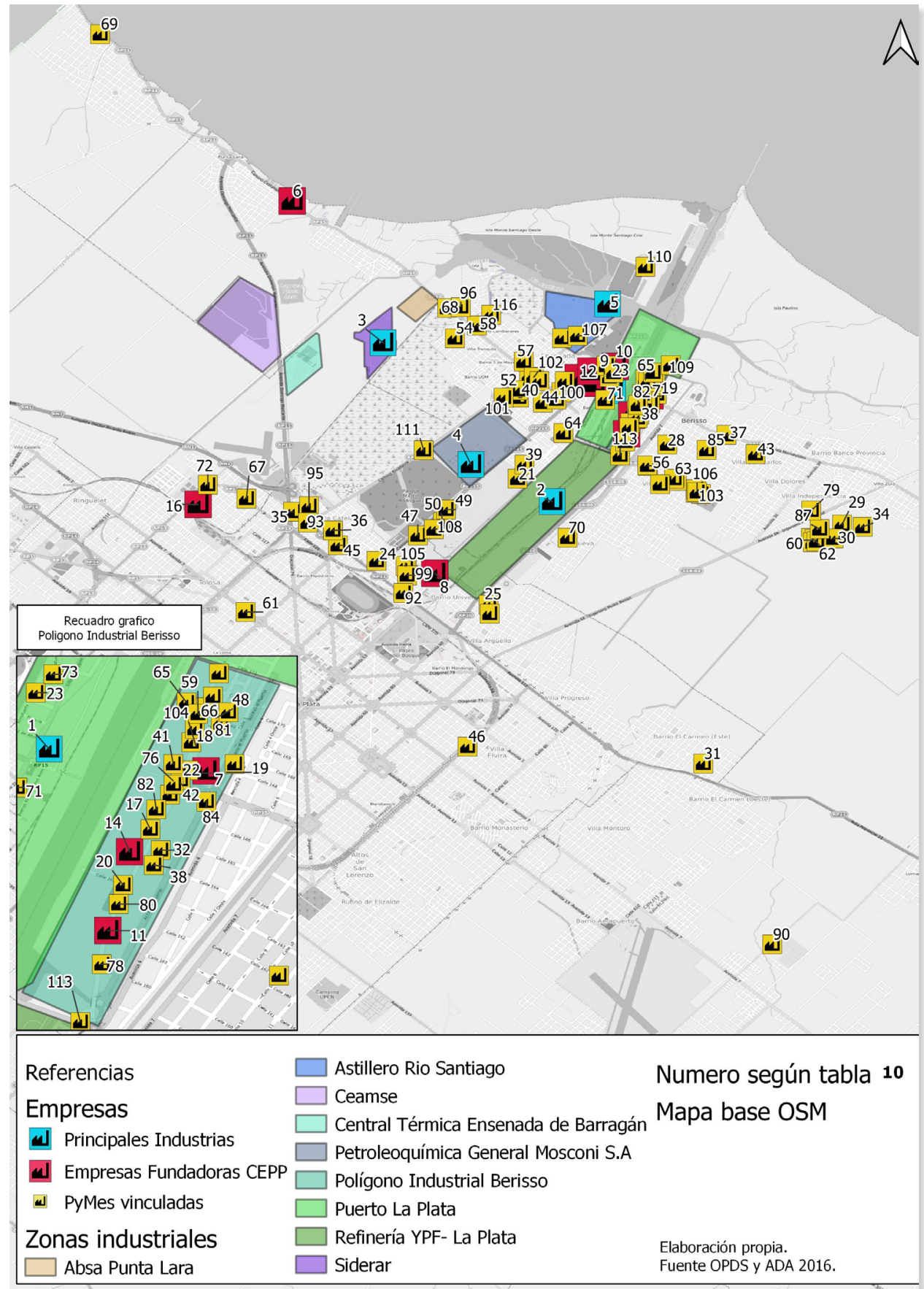

Fuente: elaboración personal con base en datos OPDS y ADA 2016

Referencia de principales industrias y Pymes de la región

$\begin{array}{llll}1 & \text { Consorcio de Gestión del Puerto La Plata } & 58 & \begin{array}{l}\text { Mauro Hernán Rocca - Fá- } \\ \text { brica de plástico }\end{array} \\ 2 & \text { Refinería YPF- La Plata } & 59 & \text { Mepla S.R.L. } \\ 3 & \text { Siderca S.A.I.C } & 60 & \text { Adeps Lanae } \\ 4 & \text { Petroquímica General Mosconi (PGM) } & 61 & \text { Grupo Plastipor } \\ 5 & \text { Astillero Rio Santiago } & 62 & \text { Faprem S.A. } \\ 6 & \text { Petrocsa - Ensenada } & 63 & \text { SRL Montajes Industriales }\end{array}$


7 Tísico S.A.Ingeniería, obras y servicios

8 Semym S.A.

9 Zarlass SA

10 Media Caña Sa

11 Coopertei Ltda

12 Nepea S.A

13 Ambiental Cooperativa de Trabajo Limitada

14 Cooperativa de Trabajo Taller Naval Ltda.

15 Sos S.A

16 Sicopro SRL

17 Productos Químicos Angeleri Jorge Carlos

18 Nogareda Rubén y Nogareda María C. S.H

19 Romadel S.R.L.

20 The ex zone S.A.

21 Coke

22 Semysistem S.R.L.

23 Carve S.A

24 Sidemo SRL

25 Acerías Berisso S.A

26

27
Adeps Lanae de Colombo Ángel L y Colombo Hugo S. de H.

Coryca S.R.L

De Simone David Ricardo

Domeniconi Microfusión SRL

E.P.A. S.R.L.

Fluxa motores y servicios S.A.

Gruas Londres SA

Metalúrgica Carlos Alberto Zapata SRL

Naviera Sur Petrolera S.A.

Coflex S.R.L.

Ciansioni Juan

Zibic S.A.

Productos Químicos Angeleri Juan Carlos

Alsina S.H.

Rabellini Juan Carlos

Ponisio Raúl Daniel

Panimex Química S.A.

Einkarem Sa

Ecopetro SA - Servicios Petroleros

Insa SA - Empresa Constructora

Pagsa - Ingenieros Argentinos SRL

Central Dique S.A.

Tecnon SRL

Petroken SA

Amiplast S.A

Arenera

Semi S.R.L

Ocemplast SRL

El pinar S.A de Istvan Oscar

y Erzetich Daniel

Marta lassi Saic

Gas Electric Americana SRL

Odin S.A
64 Usena S.A

65 Castro, Diego Nicolás

66 Lartex S.A

67 Sidemet Caños S.R.L

68 Hidrocinetic

69 Seyti Union Transitoria De Empresas

70 Solcan SRL

71 Abril Catering Group

72 Mako Constructora

73 Astillero Mo-me S.R.L

74 Ticem Sa

75 Semech SRL

76 Isometal tratamientos de pinturas SRL

77 Ecom S.A

78 Einkarem SA

79 Nodulfer Berisso S.R.L.

80 Roilmar S.A. Metalúrgico

81 Kodiplast S.H.

82 Terin S.A.

83 Recuperadora Berisso S.H.

84 Elca S.A.

85 Transelme S.R.L.

86 Antu Metalmecánica S.R.L.

87 V.V.T. S.A.

88 Horus Soluciones Tecnológicas

89 Usinage S.R.L.

90 Coargen S.A.

91 Fundición Ensenada S.R.L.

92 Manfidan

93 Gases de Ensenada S.A.

94 Meibri Srl

95 Laboratorios I.Q.P. S.R.L.

96 Air Liquide Argentina S.A

98 Gas Electric Americana SRL

99 Quimisur S.R.L.

100 MCP S.A.

101 Eme S.R.L.

102 Laboratorios plásticos S.A.

103 Coryca S.R.L

104 Naviera Sur Petrolera S.A.

105 Techne S.A.

106 Top Safe S.A

107 Logística Integral Zona Franca SA

108 Giac-Gas S.A.

109 Tec Plata

110 Escuela Naval Militar

111 Covimet Metalúrgica Sa

112 Compañía fluvial del Sud S.A.

113 Hormigonera Platense SA

114 DSL SA

115 Carlos Marzaroli S.R.L.

116 Astillero Mome

Fuente: elaboración personal con base en datos de OPDS y ADA 2016 
Cabe destacar que de las cooperativas que se formaron después de la privatización, muy pocas sobrevivieron al periodo neoliberal y aún continúan en funcionamiento con esa figura legal. No obstante, las que perduraron se consolidaron como Pymes de importancia para la región y, entre ellas, se destacan: Ambiental Cooperativa de Trabajo Limitada, Cooperativa de Trabajo Taller Naval Ltda., Coopertei Ltda., Media Caña S.A., Nepea S.A., Petrocsa - Ensenada, SEMYM S.A., Sicopro S.R.L., SOS S.A., Tísico S.A. Ingeniería, obras y servicios, y Zarlass S.A.

Es por ello que, gran parte de la actividad del resto de las Pymes depende tanto de la Refinería YPF-La Plata como de las otras industrias de relevancia del sector: Astilleros, Siderar, Propulsora, etc.

De este modo, se observa a través del trabajo de campo cómo el proceso de privatización de la década de 1990 generó una gran terciarización de la mano de obra y de la elaboración de insumos y servicios que requería YPF para su funcionamiento, generando una fuerte transformación en el empleo típico y precarizándolo (Neffa, 2010). Muchos de los trabajadores actuales de YPF son contratados por Nepea, Copertei o Media Caña y hacen trabajos dentro de la Refinería, pero la empresa no se responsabiliza de ellos sino que son subcontratados o terciarizados.

Esto se debe a dos procesos. El primero se vincula con la profesionalización cada vez más exigente y competitiva del sector. En este sentido, la compañía contrata principalmente a profesionales con experiencia y también a recién egresados con perfil proactivo, y, así, su plantilla de trabajadores está nutrida por jóvenes profesionales con especialización en el tema: ingenieros en la industria del petróleo, ingenieros civiles, industriales, electromecánicos, contadores, etc.

El segundo proceso se refiere a la terciarización y precarización laboral en tareas de mantenimiento y obra civil, donde el mayor protagonismo lo tiene el sindicato de UOCRA (Unión Obrera de la Construcción de la República Argentina) con un tipo de contratación sumamente precaria que se realiza a través de la bolsa de trabajo, abasteciendo a la Refinería en lo que refiere al trabajo no calificado.

Parte de lo expresado se refleja en el relato de estos dos tipos de trabajadores, contratados directos y terciarizados. En ellos se aprecian distintos sentidos respecto al trabajo, al lugar, al barrio y a la experiencia de transitar y vivir en ciudades industriales como Berisso y Ensenada.

Tal como expresa Manuel de 34 años, su entrada a la empresa fue por medio de la UTN y de los programas Nuevos Profesionales que promueve la empresa:

(...) entré a trabajar en Nini. Trabajé mucho tiempo ahí, cinco-seis años. Mientras trabajaba ahí estaba terminando la carrera, en ingeniería. Y cuando terminé la carrera de ingeniería empecé el profesorado. Cuando terminé el profesorado trabajé como profesor. Y mientras estaba trabajando como profesor, ahí entré a trabajar en YPF. (Manuel, 34 años, Ingeniero Industrial)

Pero también es un trabajo donde las relaciones familiares cobran importancia, dado que es muy común que algún pariente trabaje o haya trabajado en la Refinería en algún momento de su vida, (...) mi papá trabajó siempre en YPF. Creo que antes trabajaba en Propulsora, pero ya a los veintipico entró a trabajar en YPF (Manuel, 34 años, Ingeniero Industrial).

En los trabajadores subcontratados, la pertenencia a la empresa se da al margen del tipo de contratación dado que con independencia de la Pyme en la que trabajen, se sienten parte de YPF. Esto se refleja en el relato de trabajadores que son terciarizados y se recupera en la palabra de algunos de los trabajadores: 
Trabajo industrial y dinámicas socioterritoriales en las ciudades de Ensenada y Berisso. El caso de la Refinería ypF-La Plata...

En el año 2008 entré en Copetro, ahí hacía todo tarea de mantenimiento, pero en espacios verdes, hacía de todo desde cortar el pasto, fumigar y trabajo que solo ahí se te puede dar, como por ejemplo caños que pierden y te arman un producto, como la brea (...). Es uno de los peores trabajos, tiene que ir a limpiarlo (...) después de ahí pasé a una empresa en Nepea (...) está Nepea y está Petal, son empresas que tienen una particularidad, que si bien son empresas, a vos te da la ropa YPFya, y te dan cierto beneficios de YPF pero no sos de YPF. (Juan Ignacio, 38 años, trabajador de Nepea y después de YPF)

En el caso particular de este trabajador, tiempo después de la subcontratación pasa a ser planta permanente de YPF:

Hace seis años fui a YPF, hice el examen todo como si nunca hubiese estado ahí. Por ejemplo la psicóloga que me atendió me dijo vos tenés un perfil para esto. Si a vos la empresa te busca, te pone para fijarse el perfil, para ver cómo viene para estar en ese puesto, yo ya estoy en ese puesto y la mina se quedó, porque es una situación rara, es una empresa que no es YPF pero te da todas las cosas de YPF. (Juan Ignacio, 38 años, trabajador de Nepea y después de YPF)

También hay un antecedente familiar de pertenencia a la empresa, dado que su padre y abuelo trabajaron desde muy jóvenes en YPF, como manifiesta:

Mi papa fallecido trabajó en YPF (...) Yo tenía seis años cuando lo echaron y recuerdo a mi papá decirle a mi mamá bueno nos engañaron a todos en el sindicato y los echaron a todos, eso no me lo olvido más. Porque económicamente en mi familia marcó mucho. La privatización de YPF hizo cualquier desastre acá en la familia, en la región. (Juan Ignacio, 38 años, trabajador de Nepea y después de YPF)

Incluso el trabajador entrevistado manifiesta que es una llave de entrada tener algún familiar en la empresa, dado que opera como nexo de ingreso a la empresa: Por mi abuelo y mi familia. Porque ahí entras en parte por la familia, sino es muy difícil entrar, tenes que estar ligado a la suerte... (Juan Ignacio, 38 años, trabajador de Nepea y después de YPF).

La elaboración de la cartografía (Figura 5) permitió corroborar que actualmente la Cámara de emprendimientos y empresas del Polo Petroquímico está conformada por once cooperativas de trabajo -según expresó el Secretario general de SUPEH, Ramón Garaza- mientras que el conjunto de Pymes que trabajan de modo directo o indirecto para la Refinería llegan a más de 100 emprendimientos industriales. Esto demuestra la importancia de la empresa para dinamizar el mercado de trabajo en la región y en la consolidación de un polígono industrial fuertemente dependiente de la actividad productiva y económica de YPF. A nivel urbano, se puede apreciar cómo la empresa y las Pymes actúan delimitando territorio y la actividad social y comunitaria, dado que poseen una fuerte influencia en la estructura urbana de ambas ciudades.

\section{FÁBRICA Y COMUNIDAD: IMAGINARIOS URBANOS VINCULADOS A LAS NUEVAS EXPERIENCIAS LABORALES}

La ciudad como fenómeno urbano va cambiando permanentemente, es por ello que debe ser abordada tanto desde su espacialidad física como simbólica. En este sentido, las ciudades de estudio son analizadas como un espacio socialmente habitado, lo cual implica que sea percibido, representado y transitado cotidianamente por las personas que lo habitan. Es en la vivencia cotidiana, donde los sujetos sociales construyen ciertas referencias de filiación con el espacio y producen un acervo de experiencia desde el cual inscriben sus trayectorias colectivas e identitarias.

Desde el constructivismo geográfico, autores como Lindón, Hiernaux y Aguilar (2006) plantean la necesidad de enfoques que, además de estudiar la materialidad, también tengan en cuenta la dimensión simbólica del espacio urbano. La espacialidad de la vida social no puede reducirse a una realidad material y externa a las subjetividades. Ella 
debería entenderse entre la mezcla de lo imaginario y lo real, puesto que el individuo construye su propia realidad articulando lo estructural, lo funcional y lo simbólico. La cotidianidad que otorga la vivencia permite que los espacios se transformen en referentes tópicos donde los sujetos sociales cristalizan su existencia. De este modo, se construyen no solo circuitos de tránsito cotidianos donde se plasman las variadas relaciones sociales provenientes de la esfera laboral, doméstica y barrial, entre otras, sino que también se generan sitios capitales donde se desenvuelven operaciones simbólicas respecto a cómo piensan, imaginan y significan el espacio (Lindón, 2002).

Desde el nivel de lo imaginario, las figuras espaciales constituyen un material precario, sometido a la dinámica cotidiana de las acciones que los sujetos realizan en y con el espacio, pero también en diálogo con otras construcciones imaginarias. El carácter dinámico de estas formaciones imaginarias responde a una dimensión espacio-temporal que se conecta con el campo subjetivo, donde se trascienden las mediciones geométricas y se hacen posibles variadas referencias que pueden o no corresponderse con la materialidad que representan. En paralelo, la temporalidad opera en los imaginarios admitiendo distancias con respecto al tiempo medido; es decir, puede trastocar la secuencia pasado-presente-futuro reorganizándose en formas no lineales, sino impregnadas por la tensión que ejerce la subjetividad social y las sensaciones que surgen en el discurrir de las experiencias cotidianas (Lindón, 2006).

Con lo planteado, puede expresarse que si bien los imaginarios operan desde lo mental -lo que supone recorrer el espacio-temporalidad inscriptos en las figuras y sentidos que lo componen-, también es cierto que la existencia de la producción de imagos mentales y sus referencias de sentido construyen una materialidad concreta, que se visibiliza y se muestra en la recreación de los espacios. Por tanto, pese a que los imaginarios están relacionados con procesos subjetivos, cognitivos y de memoria, ello no niega que existan expresiones en formas materiales (grafitis, monumentos, puerto, fábricas, etc.); es decir, registros físicos del espacio que pueden ser duraderos o efímeros, pero que dan cuerpo a las elaboraciones de carácter simbólico (Vila y Ursino, 2013).

Esto último implica considerar la existencia de dos planos que representan la compleja constitución y configuración de un espacio: el recorrido por el campo de registros y producciones materiales que se presentan en él y, a su vez, los aspectos simbólicos que emergen en las experiencias diarias y recrean la espacialidad, poniendo en diálogo permanente ambos caminos de exploración e indagación.

El trabajo industrial y sus dinámicas producen sentidos y representaciones que atraviesan las experiencias diarias de los trabajadores y sus familias. A nivel urbano, inicialmente la Refinería delimitó un espacio fabril interno y externo, que se fue desdibujando con el tiempo y el crecimiento de la zona. El primero, hace referencia al entorno más próximo al trabajador, al lugar donde desempeña su tarea diaria y comparte la rutina laboral con superiores y compañeros. Este es puesto en tensión por la capilaridad que tiene la empresa en la vida cotidiana de sus trabajadores, y se vincula con el espacio externo, dada la influencia de la empresa en la conformación de los barrios y en la dinámica sociocultural generada para los trabajadores y su familia.

El espacio fabril refiere al ámbito de influencia de la fábrica en sí misma, y posee peso en la construcción de imagos mentales, principalmente cuando se les otorga ciertas referencias de sentido, permitiendo que esos imaginarios se visibilicen y puedan expresarse en la recreación de nuevos espacios urbanos con significado. 
En relación al espacio fabril interno, se pudo registrar diferentes vivencias en torno a compartir extensas jornadas de trabajo, situaciones laborales de riesgo, responsabilidades, trabajo en grupo como también la conformación de relaciones de amistad y compañerismo. Esto se pudo recuperar con el relato e imágenes tanto de los trabajadores actuales como de los despedidos.

Pero el oficio mío [auxiliar de planta] no te lo podés imaginar, es decir tenés que estar ahí para verlo. Si yo te lo cuento vos decís este tipo mucho no hace, pero bueno. Pero básicamente es controlar, abrir y cerrar válvulas, controlar niveles, hay niveles que si suben son peligrosos, hay niveles que si bajan también, hacen que el proceso se te dificulte más cosas (....) si bien están los mecánicos que los arreglan, somos nosotros lo que las cuidamos, los responsables. (Julio, trabajador de Nepea)

En las expresiones de este trabajador se refleja la importancia de la vivencia diaria en el lugar de trabajo y se vincula la peligrosidad del mismo, donde lo que parece sencillo a la mirada ajena "abrir y cerrar válvulas, controlar niveles, hay niveles que si suben son peligrosos", requiere de un saber técnico especializado que implica responsabilidad y compromiso. Es un trabajo que conlleva riesgos permanentemente y no se puede improvisar, dado que se pone en riesgo la vida propia y la del compañero, tal como relata Julio:

(...) esa persona que está ahí tiene al lado 300 metros de altura, al lado tiene un caño que tiene soda cáustica, por ahí lo menos tecnificado un oficio que no necesites tanta experiencia estar ahí dentro requiere igual saber muchas cosas. (Julio, trabajador de Nepea e hijo de ex trabajador de YPF)

Pero también refiere a cómo fue cambiando ese lugar de trabajo, las medidas de seguridad al interior de la Refinería "a mí me dan un lugar como este con aire acondicionado, un televisor escondido porque no se puede tener, pero lo tenemos para alivianar la noche, tenemos un grill (...) tenemos papel para higienizarse, jabón, agua caliente, te dan todo eso en la empresa". Esto muestra diferencias respecto a la experiencia laboral del padre y abuelo.

A su vez, los espacios comunes como el comedor diario o los lugares de guardia continúan existiendo pero muchas veces el ritmo de trabajo hace que el intercambio de pares sea mucho menor o para personal jerarquizado, como refiere Manuel:

Acá abajo, hay otro edificio y hay un salón comedor, que yo puedo comer ahí, o esta gente de acá que tienen trabajos administrativos o de programación, se juntan en la oficina y comen. Yo estoy solo en la oficina, a veces voy a comer con ellos, depende como va (...) Se hace largo el día. Yo tengo una actividad bastante solitaria acá, en la función. (Manuel, ingeniero trabajador de YPF)

A pesar de la jerarquía, la posibilidad de compartir un momento con los compañeros sigue existiendo, dada la cantidad de horas que se trabajan y el sistema rotativo de días, que como expresan los entrevistados, al comienzo se hace difícil pero se acostumbran e, incluso, algunos se sienten beneficiados:

Y trabajar en turnos no es fácil. Porque vos trabajás cuatro días de día, de 6 am a 6 pm. Después tenés cuatro francos, está bueno porque se van corriendo los días. No es de lunes a jueves. Se van corriendo de a un día, porque vos trabajás cuatro, después tenés cuatro días de franco y trabajás otros cuatro (...) Hay una revolución física y mental que hay que ir llevándola, no es fácil. No te alcanza el tiempo para adaptarte al cambio de horarios, Ilega un momento que estás fatigado, mentalmente y físicamente. (Manuel, 35 años, ingeniero trabajador de YPF e hijo de Operario de YPF)

En estas palabras se observa cómo la empresa continúa atravesando la vida familiar, se apropia de momentos de la vida cotidiana de los trabajadores y coloniza esos espacios, puesto que es algo que persiste en el relato de los ex trabajadores y en los hijos que, actualmente, trabajan en la empresa.

No te acostumbrás al cambio de horario. Es más, te afecta. A la gente que está con veinte años yo veo que le afecta, en el sueño, en un montón de cosas. Cuando es el cambio de día a noche, después en el franco lo mismo. En el fran- 
co, los dos días que ya te acostumbraste a dormir hasta las diez, ya después te tenés que acomodar. Es un trastorno. Yo en principio lo vi a mi viejo o gente conocida que laburaba y estaba, dentro de todo, bien. (Julián, 26 años, trabajador de Nepea e hijo de ex trabajador de YPF)

Yo lo viví con mi papá, que trabajó siempre de turno, y no siempre estaba para ir a la escuela, para un cumpleaños, cada tanto le tocaba trabajar. Después con la antigüedad y con la facilidad que te dan los compañeros, tenés más posibilidades de hacer un cambio, de facilitarte esas horas que vos necesitás para momentos especiales. (Manuel, 35 años, ingeniero trabajador de YPF e hijo de operario de YPF)

En el caso de Manuel y de los otros trabajadores, se aprecia el valor que se le da al compañerismo, sobre todo al momento de cambiar días de franco, compartir jornadas muy extensas de trabajo, actividades de riesgo, etc.

Respecto al espacio externo, la Refinería fue marcando el ritmo de la urbanización y la imagen externa sigue siendo un referente en la construcción de sentidos vinculados al trabajo y a la ciudad. Esto se puede apreciar en la Figura 6 y en los siguientes relatos:

Figura 6. Barrio histórico de YPF ubicado en la ciudad de Ensenada

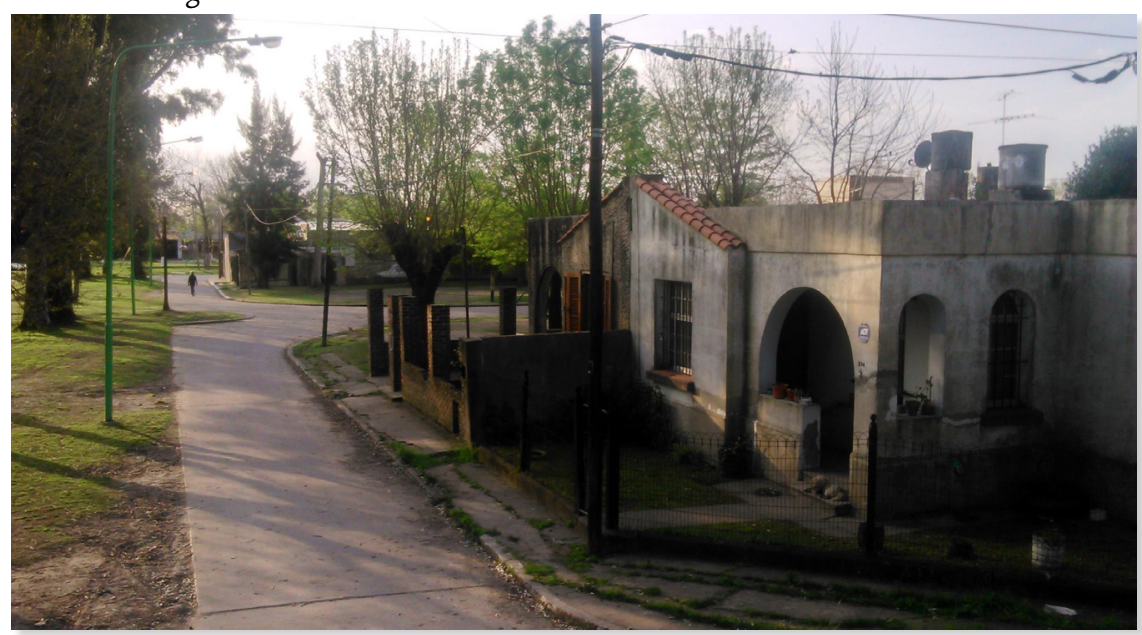

Fuente: registro fotográfico de trabajo de campo, octubre de 2016

Eran empresas importantes (...) Y vos fíjate que YPF se construye y después se construyen barrios en la periferia, como el barrio de YPF que está yendo para Berisso, frente a la estación de servicio, ese barrio era de YPF, era para la gente trabajadora de YPF. Y después, dentro de la misma destilería, había un barrio que era para los jefes. (Pedro, trabajador de Petroquímica)

Es una ciudad de los caños, como le dicen. "Cómo voy a aprender esto" decís. Y bueno, con el tiempo, lo vas Ilevando. Es más, yo hace cinco años. Un operador ahí adentro para estar bien, manejarse bien, necesita siete años. Siempre aprendes cosas nuevas, cuando van saliendo laburos nuevos, cosas nuevas. Aparte es un laburo complicado. Mucho riesgo. Es inmenso, la planta que estamos nosotros es grande. Hay plantas más chiquitas pero también hay mucho riesgo. (Julián, 26 años, trabajador de Nepea e hijo de ex trabajador de YPF)

"Nacimos mirando la estación de YPF" (Julio, trabajador de Nepea y ex trabajador de YPF). Esta expresión muestra los sentidos y significados que se ponen en juego al momento de hablar de la Refinería en tanto fábrica que desde el recuerdo de cada entrevistado siempre estuvo presente, ya sea por su impronta física, por representar el lugar de trabajo de gran parte del grupo familiar, por formar parte de los festejos locales, por el riesgo ambiental o por la actividad económica que genera a ambas ciudades, principalmente a la de Ensenada. Es por ello que su presencia excede la materialización física y determina fuertemente la construcción de identidad de sus trabajadores, expresada en sus prác- 
ticas espaciales, en las representaciones que tienen de ese espacio y en los espacios de representación que serán abordados en el siguiente apartado.

A nivel social, actualmente la empresa continúa estableciendo vínculos de integración socio-comunitaria por medio de la oficina de Relaciones Institucionales de YPF y las ejecuta en cuatro acciones:

1) Recreativa: posee el Espacio de la Energía y hacen visitas guiadas a escuelas, grupos de profesionales, centros barriales, etc.

2) Plan de Actuación ante emergencias con Impacto en la Comunidad (PREIC). Este plan de actuación fue formalizado en la firma de un acta de compromiso. Del acuerdo participaron la municipalidad de La Plata, Berisso y Ensenada, Prefectura Naval, Consorcio Puerto La Plata, Air Liquide, Buenos Aires Zona Franca, Camuzzi Gas Pampeana, Copetro, Petroquímica Cuyo, YPF SA, Defensa Civil, Bomberos Voluntarios de Berisso y de Ensenada. La comunidad también es, de forma implícita, parte del compromiso, con la participación de representantes barriales de El Dique, Barrio Universitario y Mosconi.

3) Educativo: tiene una cátedra de Industrialización de Hidrocarburos en la UTN y UNLP. Hacen simulacros y donaciones en escuelas.

4) Social: participan de iniciativas de los sindicatos SUPEH y UOCRA, realizan donaciones en escuelas, hospitales, como también capacitaciones gratuitas.

Este accionar se caracteriza por tener un perfil principalmente asistencialista/paternalista, y tiene por finalidad promover la integración socio comunitaria de la empresa con ambas ciudades, sin embargo, no tiene gran visibilidad dado que gran parte de los entrevistados lo desconoce o participan muy poco en dichas actividades. En lo que respecta al impacto socioambiental y al PREIC específicamente, si bien es una iniciativa valiosa para la comunidad no contempla la incertidumbre de vivir en ciudades rodeadas por una Refinería y un conjunto de empresas de características similares, que generan exposiciones diarias a gases y hollín.

En las Figuras 7 y 8 se muestra el impacto de la empresa en el espacio externo, o sea la influencia de la Refinería en el entorno barrial y en la dinámica social y cultural que generó por medio de actividades vinculadas a los trabajadores y sus familias. En la Figura 7 se puede ver la cercanía de la Refinería a la población, dado que lo único que la separa de los barrios son los canales, que presentan signos de contaminación e indican un riesgo potencial para la población. En la Figura 8 se puede ver cómo son apropiados los espacios más próximos al lugar de trabajo, donde el entorno inmediato se convierte en un estacionamiento masivo para los automóviles del personal. No obstante, en el caso de los que se manejan en transporte público, es llamativo observar el desfile de estos trabajadores vestidos de overol azul inundando las calles más próximas a los barrios Mosconi e YPF de Ensenada.

Finalmente, se pudo mostrar cómo el espacio fabril interno y externo no son espacios estancos sino que se vinculan entre sí, e inciden en las representaciones espaciales de los trabajadores y ex trabajadores, dado que la empresa construye lazos que tienen una expresión tanto física como simbólica. Esto último se refleja en el recuerdo de los trabajadores, en sus vínculos familiares y en las relaciones laborales. A su vez, la fuente de trabajo construye subjetividades e identidades que van más allá de lo laboral, dado que atraviesan los espacios de la vida familiar y barrial, expresadas en un lugar que es apropiado simbólicamente. 
Figura 7. La Refinería YPF-La Plata y los canales

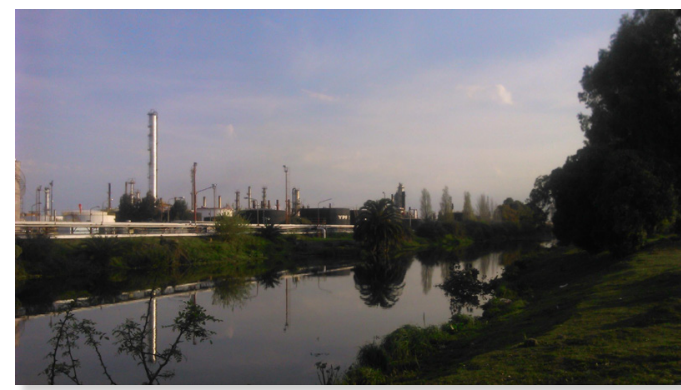

Fuente: registro fotográfico de trabajo de campo, octubre de 2016
Figura 8. Espacios circundantes a la Refinería YPF-La Plata

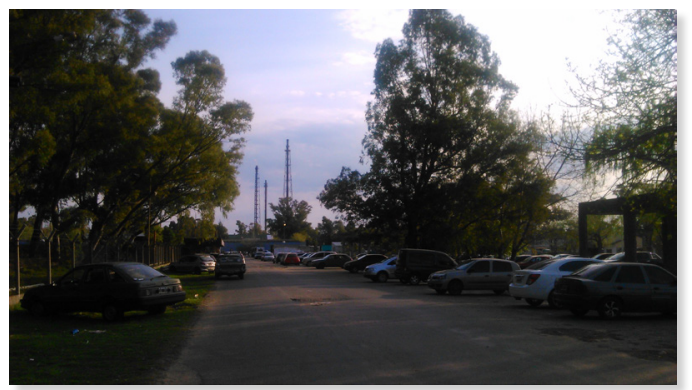

Fuente: registro fotográfico de trabajo de campo, octubre de 2016

\section{REFLEXIONES}

En este trabajo se dio cuenta del impacto social y territorial que tiene el trabajo industrial en las ciudades de Berisso y Ensenada, y se hizo hincapié en un establecimiento insignia de ambos lugares: la Refinería YPF-La Plata.

El recorrido histórico permitió caracterizar el devenir de la empresa, el cual se encuentra atravesado por diferentes momentos sociales y políticos del país que se tradujeron tanto a escala urbana como regional, por la jerarquía de la empresa en la estructura social de la Región del Gran La Plata. En este sentido, ambas ciudades han tenido un papel relevante a nivel socioeconómico, debido a la intensa actividad industrial de gran repercusión para la zona y su población.

La empresa estatal promovió un modelo de integración social y territorial anclada en el paternalismo empresarial, el cual estaba fuertemente ligado a la cultura del trabajo, a la vida comunitaria y social. De este modo, se pudo analizar que los vínculos existentes entre la fábrica y la comunidad a escala urbana se visualizan en las transformaciones espaciales de ambas ciudades. Los mapas del primer proceso de urbanización reflejan cómo los procesos políticos y económicos inciden en la conformación física de las ciudades. Pero, la estructura física no es lo único importante, sino también los sentidos y significados que se construyen sobre la fuente de trabajo y la ciudad. Estos elementos simbólicos participaron activamente en la construcción de los imaginarios urbanos que poseen los sujetos sobre el lugar en el que viven y al cual los une un fuerte sentimiento de pertenencia.

Los cambios en el mundo del trabajo y los nuevos modos de organización, sin lugar a duda, transformaron las identidades de los trabajadores industriales. Las nuevas formas de contratación son más inestables como también precarias, dado que muchas se realizan por empresas terciarizadas o por medio de bolsas de trabajo de los sindicatos. Ello implica contratos de un tiempo limitado que hace más difícil la construcción de vínculos con los compañeros de trabajo y con la empresa misma. La pertenencia a YPF, como a los beneficios sociales que otorgaba, generó un sentido de identidad compartida con los compañeros que iba más allá del lugar de trabajo, dado que trascendía a otros espacios de la vida cotidiana como el barrio y la familia.

Las consecuencias de la privatización en el año 1993, producto del proceso de racionalización de personal -despidos masivos- interpeló fuertemente a los trabajadores, a la vida familiar y a la cotidianeidad de ambas ciudades. De esta manera, se puedo apreciar 
cómo en momentos de crisis económica, el trabajo y el lugar, en este caso Berisso y Ensenada, funcionaron como elementos simbólicos que estructuraban la identidad de los trabajadores y ex trabajadores vinculados a YPF. Por medio del trabajo de campo se registró la percepción que posee el trabajador-habitante de los cambios a nivel urbano, donde se tuvo en cuenta la secuencia pasado-presente-futuro en las representaciones que poseen del espacio que habitan.

A nivel económico se caracterizó la reestructuración industrial del Gran La Plata que fue particularmente significativa en las grandes industrias, como consecuencia de la privatización de empresas estatales como YPF, la reconversión de procesos productivos, la racionalización de plantas, la extranjerización y la concentración de capitales.

En el caso de la Refinería YPF-La Plata, las estrategias de los trabajadores tuvieron diferentes particularidades debido al proceso de privatización, alcanzando incrementos en productividad y competitividad a través de racionalización de planteles, terciarización de segmentos de la producción y reconversión de tecnologías.

Ante el despido masivo, parte de este personal que estaba altamente calificado conformó cooperativas de trabajo y Pymes que aún en la actualidad trabajan de manera terciarizada para la Refinería. La conformación de estas empresas ayudó a mitigar los efectos de la desocupación y al absorber parte de la mano de obra despedida, la protesta social fue apaciguada en la región. Estas Pymes fueron registradas y mapeadas en la Figura 5 para dar cuenta de cómo la privatización de la empresa más importante de la región incide considerablemente en la estructura urbana de ambas ciudades.

Este escenario de precarización laboral y desinversión productiva se profundizó a partir de la crisis del año 2001 y empeoró durante el año 2002. El efecto de la convertibilidad a nivel de política industrial fue totalmente nocivo y desalentador, dado que la consecuencia de un peso sobrevaluado hacía difícil competir tanto en los mercados mundiales como también en el interno, lo cual generó un retroceso en las exportaciones industriales.

Finalmente, la nacionalización en el año 2012 renovó sentidos asociados a la soberanía e industria nacional, enmarcados en un proyecto populista que se apoyaba en el fomento de la industria y en la generación de nuevas fuentes de trabajo. Esto último, se vio reflejado en las políticas públicas destinadas a las Pymes y a las cooperativas de trabajo que estaban orientadas tanto al mercado interno, como también en medidas vinculadas a fortalecer la integración socio-comunitaria de la empresa con las ciudades donde se instala, en nuestro caso, Berisso y Ensenada.

\section{REFERENCIAS}

Adriani, H.L. (2014). El sector industrial del Gran La Plata en la posconvertibilidad. III Jornadas Nacionales sobre estudios regionales y mercados de trabajo. Universidad Nacional de Jujuy. Facultad de Ciencias Económicas y Unidad de Investigación en Comunicación, Cultura y Sociedad de la Facultad de Humanidades y Ciencias Sociales y Red SIMEL.

Adriani, H.L.; Langard, F. y Steimberg, J. (2011). El sector industrial del Gran La Plata durante el régimen de convertibilidad, su crisis y la etapa de crecimiento económico. En H.L. Adriani, M.M. Papalardo, P.A. Pintos y M.J. suárez (Comps.) Actores, Estrategias y Territorio. El Gran La Plata: de la crisis de la convertibilidad al crecimiento económico. La Plata: Universidad Nacional de La Plata.

Adriani, H. y Arturi, D. (2015). La reestructuración productiva en las grandes indus- 
trias. Análisis particularizado de la Destilería YPF. En D. Lan, H.L. Adriani y E. Spósito (Comps.) Reestructuración productiva e industria, en ciudades intermedias de Argentina y Brasil. Argentina: Universidad Nacional del Centro de la Provincia de Buenos Aires.

Ardenghi, P. y Adriani, H.L. (2014). Las fábricas recuperadas en la posconvertibilidad: Estudio de caso en el Gran La Plata. XVI Jornadas de Investigación del Centro de Investigaciones Geográficas y del Departamento de Geografía. La Plata, 1 al 2 de octubre de 2014. Universidad Nacional de La Plata. Facultad de Humanidades y Ciencias de la Educación. Centro de Investigaciones Geográficas.

Azpiazu, D. y Basualdo, E. (2004). Las privatizaciones en la Argentina. Genesis, desarrollo y principales impactos estructurales. En Las privatizaciones en la Argentina. Genesis, desarrollo y principales impactos estructurales. Argentina: FLACSO, Facultad Latinoamericana de Ciencias Sociales.

Balazote, A. y Radovich, J.C. (2000). Efectos sociales de la privatización de YPF en la provincia del Neuquén. Cuadernos del Instituto Nacional de Antropología y Pensamiento Latinoamericano, 19, 71-88.

Basualdo, E.M. (2006). La reestructuración de la economía argentina durante las últimas décadas de la sustitución de importaciones a la valorización financiera. En E. Basualdo y E. Arceo Neoliberalismo y sectores dominantes. Tendencias globales y experiencias nacionales. Buenos Aires: CLACSO.

Beccaria, L.; Esquivel, V. y Maurizio, R. (2000). Desigualdad y polarización del ingreso en argentina. Buenos Aires: Universidad Nacional de Gral. Sarmiento.

Berberena, A. y Marcos, M.F. (1997). La reinserción laboral de los empleados desplazados del Estado: el caso de la Destilería La Plata de YPF. Instituto Nacional de la Administración Pública. Serie II, Estado y sociedad, Documento Nº 38. Buenos Aires.

Bonnet, F.; Figueiredo, J. y Standing, G. (2003). Una familia de índices de trabajo decente. Revista Internacional del Trabajo, 122(2).

Ciffarelli, V. y Martínez, O. (2009). Clase obrera y movimiento obrero en Argentina, situación y desafíos. Revista Theomai, (19), 97-117.

Cotarelo, M.C. (2005). Recursos naturales y conflicto social en la Argentina actual. OSAL, Observatorio Social de América Latina, 17.

Figari, C. y Palermo H. (2010). Disciplina laboral, precarización y subjetividades en la industria petrolera. En J. Neffa y E. De la Garza (Coords.) Trabajo, identidad y acción colectiva. UAM/ Iztapalapa: Plaza y Valdés Editores. Madrid: CLACSO.

Frassa, J.; Muñiz Terra L. y Naclerio A. (2010). Trayectorias empresariales divergentes frente a contextos de privatización. Un estudio comparativo de dos empresas públicas argentinas. Economía, Sociedad y Territorio, X(32), 179-206.

Goodman, L. (1961). Snowball Sampling. The annals of Mathematics Statistics, 32,(1).

Guiotto, L. (1979). La fabbrica totale. Paternalismo industriale e città sociali in Italia. Milano: Feltrinelli economica.

Langard, F.; Arturi, D y Adriani, L. (2012). El sector industrial del Gran La Plata en el neoliberalismo. Aproximación a sus transformaciones a través de los Censos Nacionales Económicos. Revista de Estudios Regionales, (8), 7-30.

Lindón, A. (2002). Trabajo, Espacios de vida y Cotidianidad. La periferia oriental de la ciudad de México. Revista Electrónica de Geografía y Ciencias Sociales Scripta Nova, 119.

Lindón, A. (2006). Lugares e imaginarios en la metrópolis. México: Anthropos. 
Lindón, A.; Hiernaux, D. y Aguilar, M.A. (2006). De la espacialidad, el lugar y los imaginarios urbanos: a modo de introducción (pp. 9-26). En A. Lindón, M.A. Aguilar y D. Hiernaux (Coords.) Lugares e imaginarios en la metrópoli. Barcelona: Anthropos-UAM-I.

Lobato, H. (2001). La vida en las fábricas. Trabajo, protesta y política en una comunidad obrera, Berisso (1904-1970). Buenos Aires: Entrepasados/Prometeo.

Morosi, J.A. (1999). Ciudad de La Plata. Tres décadas de reflexiones acerca de un singular espacio urbano (1a ed.). Laboratorio de Investigaciones del Territorio y el Ambiente.

Morosi, J.A. (1983). La Plata, Ciudad Nueva, Ciudad Antigua. Historia, forma y estructura de un espacio singular. La Plata: Universidad Nacional de La Plata.

Muñiz Terra, L. (2007). Caminos truncados. Un estudio de las consecuencias de la privatización de YPF en las trayectorias laborales de los ex trabajadores petroleros. Tesis de maestría. Buenos Aires: Mimeo.

Muñiz Terra, L. (2008). La pérdida del trabajo petrolero. Transformaciones laborales, materiales e identitarias. Revista Avá, 12.

Muñiz Terra, L. (2012). Los ex trabajadores de YPF. Trayectorias laborales a 20 años de la privatización. Buenos Aires: Espacio Editorial.

Neffa, J. (2010). La transición desde los "verdaderos empleos" al trabajo precario. En E. De La Garza y J. Neffa (Coords.) Trabajo, identidad y acción colectiva. México: Plaza y Valdés.

Odisio, J. (2015). La experiencia de Petroquímica General Mosconi como "mirador" del cambio en la estrategia económica de la Argentina entre 1970 y 1993. Terceras Jornadas de Historia Económica. El Colegio de México. Recuperado de www.amhe.mx/jornadas/ ponencias2015/Ponencia\%20Odisio.pdf

Palermo, H. (2015). Apuntes para pensar la nacionalización de YPF: relaciones laborales y tensiones sociales en Comodoro Rivadavia (1a edición). Ciudad Autónoma de Buenos Aires: CLACSO.

Pesoa, M. y Sabaté, J. (2016). La Plata y la construcción de un pais. Del papel a la realidad. Coloquio Internacional de Geocrítica Las utopías y la construcción de la sociedad del futuro. Barcelona, 2 al 7 de mayo.

Ravella, O. y Giacobbe, N. (2001). El pasado y el Presente en la sustentabilidad urbana. El caso de la ciudad de La Plata, Argentina. Actas, 8.

Russo, C. (2008). Fábrica y localidad. La construcción de la identidad industrial: el caso de la cervecería y maltería Quilmes. Revista H-industria, 2(II), 153-174.

Svampa, M. y Pereyra, S. (2009). Entre la ruta y el barrio: la experiencia de las organizaciones piqueteras. Editorial Biblos.

Torres, F. (2011). Territorio y lugar: potencialidades para el análisis de la constitución de sujetos políticos: El caso de un movimiento de desocupados en Argentina. Geograficando, año 7(7), 209-238.

Torres, F. (2012). La privatización de YPF en Comodoro Rivadavia. Algunas características y consecuencias sociales y laborales. Revista Trabajo y Sociedad, (18).

Vila, M. y Ursino, S. (2013). El territorio, los procesos de producción y apropiación del espacio en los sectores populares latinoamericanos. Proyecciones, VII(15), 114 -134.

\section{OTRAS FUENTES}

Autoridad del Agua (ADA) (2016). Recuperado de http://www.ada.gba.gov.ar/ Instituto Nacional de Estadística y Censos INDEC (1974). Censo Nacional Económico. 
Instituto Nacional de Estadística y Censos INDEC (1985). Censo Nacional Económico.

Instituto Nacional de Estadística y Censos INDEC (1994). Censo Nacional Económico.

Instituto Nacional de Estadística y Censos INDEC (2004). Censo Nacional Económico.

Organismo Provincial de Desarrollo Sostenible (OPDS) (2016). Recuperado de http:// www.opds.gba.gov.ar/

Yacimientos Petróliferos Fiscales YPF. Recuperado de https://www.ypf.com/LaCompania/Paginas/Produccion.aspx

Sandra Valeria Ursino es Doctora en Arquitectura y Urbanismo, especialista en el estudio de las representaciones sociales e imaginarios urbanos vinculados a ciudades medias industriales. Magister en Paisaje, Medio Ambiente y Ciudad. Licenciada en Sociología. Investigadora del Centro Interdisciplinario de Estudios Complejos de la Facultad de Arquitectura de la UNLP (CIEC/FAU). Docente de la cátedra de Teorías y Planeamiento Territorial I y II desde el año 2012 (FAU/UNLP). Posee una trayectoria profesional y actividad académica vinculada al estudio de los procesos de producción y apropiación simbólica del espacio urbano, con énfasis en la experiencia urbana de los sujetos-habitantes y en la planificación urbano/territorial participativa. Centro Interdisciplinario de Estudios Complejos. Facultad de Arquitectura y Urbanismo. Universidad Nacional de La Plata (CIEC/FAU/UNLP). Calle 47 N¹62, (1900) La Plata, Buenos Aires, Argentina, sandraur@hotmial.com, ORCID https://orcid.org/0000-0002-6136-5105 